\title{
BANDAR UDARA INTERNASIONAL JAWA BARAT (BIJB) SEBAGAI HUB LOGISTIK INTERNASIONAL di JAWA BARAT
}

\author{
Joni Gusmali ${ }^{1}$, M. Fatchoelqorib ${ }^{2}$, Sugiarti $^{3}$, Lutik Astri ${ }^{4}$ \\ ${ }^{1,2,3,4}$ Sekolah Tinggi Penerbangan AVIASI, Jakarta, Indonesia
}

email : joni.selayan@gmail.com, fatchoelq@gmail.com, ugiart77@gmail.com, lutikastri@yahoo.com

ABSTRACT
The aim of this research is to giving an illustrate about the chance of Kertajati
Airport as International hub of logistic in West Java. Kertajati Airport which is located in
Majalengka one of the distric in West Java, have a good possibility to become a center
point for international air traffic and logistic, refer to its strategic location as crossing
point for two seaport in Cirebon, Port Muara Jati and Port Patimban. In term of
geographical point of view, this should be a good chance for government and authorities
to take advantages by managing the operation of those airports: Kertajati, Husein
Sastranegara, Halim Perdanakusuma, Soekarno-Hatta and surrounding seaports like Port
Muara Jati and Port Patimban in integrated method. The integrated operation which
necessarily supported by high accessibility and good infrastructure can generate
economic growth indeed by giving opportunity for small and medium enterprises around
to increase their products, whether for domestic or international markets. This also can
afford escalation on dynamics trades and investments in West Java. Therefore Kertajati
Airport could be considered as an alternative solution for traffic jam and over capacity
problem, in the context of cargo shipping at Soekarno-Hatta Airport.
Keywords:hub airport, logistic, integrated transportation, small and medium enterprises
a




\section{PENDAHULUAN}

Beberapa pelaku logistik berkeinginan untuk menggarap pasar kargo antara Jawa dengan Singapura dan Batam melalui Bandara Kertajati (KJT). Penyebaran kargo melalui Bandara KJT dapat mengurangi resiko keterlambatan pengiriman kargo bila melalui Bandara Soekarno Hatta (CGK) karena kemacetan jalan darat dari Cikampek, Karawang, Bekasi ke arah Bandara CGK. Penerbangan kargo ini mendukung pertumbuhan Bandara KJT khususnya dan perekonomian Jawa Barat pada umumnya.

Maskapai jangkar (maskapai yang berminat menjadikan BIJB sebagai hub/homebase) dapat mendukung operasional penerbangan kargo tersebut. Selain itu, maskapai jangkar dapat menyiapkan analisis pasar dan aspek operasionalnya.

Beroperasinya tol CileunyiSumedang-Dawuan (Cisumdawu) ke depannya diharapkan dapat menyelesaikan masalah masih kurangnya penumpang dan barang yang datang dan berangkat dari wilayah Bandung Raya.

Masyarakat dari kawasan Cirebon, Indramayu, Majalengka, dan Kuningan akan lebih mudah dan nyaman berangkat dari Bandara KJT dibanding harus ke bandara Husein atau ke Bandara CGK. Jalan tol layang (elevated) Jak arta-Cikampek sudah beroperasi maka calon penumpang pesawat dari Bekasi, Cikarang, Karawang juga akan lebih mudah menjangkau BIJB.

Secara demografis, Bandara Kertajati di Kabupaten Majalengka dianggap menjadi titik temu dan dianggap menjadi lokasi strategis sebagai pusat arus lalu lintas udara internasional dan logistik dari dua pelabuhan, yaitu Pelabuhan Muara Jati Cirebon dan Patimban.

Bandara Kertajati di Majalengka tidak akan menjadi hub udara tanpa kemauan politik yang kuat dan keputusan yang cepat dari pemerintah. Setelah reformasi, angkutan udara makin memainkan peran penting di Majalengka untuk menjaga pertumbuhan ekonomi dan mendukung niatnya menjadi pusat logistik udara. Seiring dengan upaya negara untuk meningkatkan industrialisasi dan membangun pariwisata serta industri logistik di Indonesia bagian barat dan tengah, maka pemanfaatan Bandara KJT tepat waktu dan didukung oleh aksesibilitas yang tinggi dan memadai akan lebih mendorong pertumbuhan ekonomi Jawa Barat melalui perdagangan dan investasi.

Peluang bagi pemerintah dan otoritas bandara adalah dapat mengelola Kertajati, Husein Sastranegara, Halim Perdanakusuma, Soekarno-Hatta serta pelabuhan laut sekitarnya sebagai bandara dan pelabuhan yang terintegrasi dalam konteks operasi 
bandara dan pelabuhan. Operasional bandara dan pelabuhan tersebut dapat difokuskan pada konsep integrated multi-port and airport system. Integrated multi-port and airport system ini juga mendukung pengembangan area megapolitan di Jawa Barat hingga Jabodetabek.

\section{BATASAN MASALAH}

Dalam penelitian ini dibatasi hanya membahas tentang BIJB sebagai hub logistik internasional di Jawa Barat.

\section{TUJUAN PENELITIAN}

Tujuan dari penelitian ini sebagai berikut :

1. Menjadikan Bandara Kertajati di Majalengka sebagai hub logistik terutama untuk e-commerce.

2. Menjadikan UKM Jabar dapat mendunia lebih cepat dengan dijadikannya Bandara Internasional Jawa Barat (BIJB) menjadi hub untuk kargo terbesar di Indonesia.

\section{LANDASAN TEORI}

Menurut UU No. 1 Tahun 2009 tentang Penerbangan, bandar udara adalah kawasan di daratan dan/atau perairan dengan batasbatas tertentu yang digunakan sebagai tempat pesawat udara mendarat dan lepas landas, naik turun penumpang, bongkar muat barang, dan tempat perpindahan intra dan antar moda transportasi, yang dilengkapi dengan fasilitas keselamatan dan keamanan penerbangan,

serta fasilitas pokok, dan fasilitas penunjang lainnya.

Bandar udara pengumpul (hub) adalah bandar udara yang mempunyai cakupan pelayanan yang luas dari berbagai bandar udara yang melayani penumpang dan/atau kargo dalam jumlah besar dan mempengaruhi perkembangan ekonomi secara nasional atau berbagai provinsi.

Kata logistik berasal dari bahasa Yunani logos yang berarti "rasio, kata, kalkulasi, alasan, pembicaraan, orasi”. Kata logistik memiliki asal kata dari bahasa Prancis loger yaitu untuk menginapkan atau menyediakan. Sejarah logistik berasal dari pihak militer yang harus mempersiapkan pasokan untuk persediaan kegiatan militer.

Kargo adalah barang kiriman yang diangkut melalui jalur udara, darat, dan laut yang dikenakan biaya pengiriman yang ditentukan oleh pihak pengangkut dan tercatat dalam dokumen Surat Muatan Udara (SMU) pada penerbangan domestik atau Air Way Bill (AWB), Bill of Lading (B/L) pada penerbangan atau pengapalan internasional.

Konsep integrated multi-port adalah konsep pelabuhan multi yang terintegrasi. Konsep airport system adalah konsep sistem bandar udara. Hubungan konsep ini bisa menjadi satu kesatuan yang baik untuk menjadikan transportasi nasional yang terpadu. 


\section{METODE PENELITIAN}

Berdasarkan data yang diperoleh dapat dilihat bahwa data ini berupa data statistik deskriptif. Data statistik deskriptif tersebut hanya menjelaskan data-data yang sudah ada. Data-data tersebut bisa dijelaskan untuk mengetahui perbandingan sampel. Diketahui perbandingan data Bandara Kertajati bulan Juli-Desember 2019 dan data Bandara Husein Sastranegara bulan JuliDesember 2019. Data kedua bandara tersebut berisi jumlah penerbangan, jumlah barang, dan jumlah pos. Data tersebut bisa menjadi gambaran seberapa besar persentase kargo di Bandara Kertajati dan Bandara Husein dalam periode bulan Juli-Desember 2019.

\section{OBJEK PENELITIAN}

Sebagai perbandingan, pasar pada tahun 2019 dari CGK ke Batam (BTH) pulang pergi (p.p). yaitu 53 ton barang per hari dan dari CGK ke SIN p.p. sebesar 279 ton barang per hari. Bila dari jumlah tersebut dialihkan 20 persen ke BIJB maka perlu disiapkan kemampuan BIJB untuk incoming dan outgoing sebanyak 66 ton per hari.

Untuk meramaikan logistik internasional di BIJB dapat dibangun Rute KJT-Singapura Seletar (XSP) atau Changi (SIN) dan dikondisikan untuk bisa menangani barang cepat rusak (perishable) seperti ikan, sayuran, buah-buahan, obatobatan, dan barang umum (genco) seperti garment dan furniture. Rute tersebut diintegrasikan dengan Rute XSP/SIN-BTH untuk menampung barang umum dan dilanjutkan dengan jalur BTH-KJT untuk Barang umum seperti e-commerce product dengan pasar potensial sebesar 15s.d.20 ton per hari.

Sampai akhir tahun 2019 kinerja kargo incoming dan outgoing BIJB baru mencapai rata-rata 4 ton per hari. Volume tersebut lebih rendah dari rata-rata sebelumnya di Bandara Husein Sastranegara yaitu 23 ton perhari. Hal ini merupakan keadaan sebelum wabah tetapi setelah adanya wabah angka ini banyak mengalami penurunan.

\section{Tabel 1 Data Bandara Kertajati Juli-}

\begin{tabular}{|c|c|c|c|c|}
\hline Rute & $\begin{array}{l}\text { Jumlah } \\
\text { Pnb. }\end{array}$ & $\begin{array}{c}\text { Jumlah } \\
\text { Barang } \\
\text { (kg) }\end{array}$ & $\begin{array}{l}\text { Jml. } \\
\text { Pos } \\
(k g)\end{array}$ & $\mathbf{L} / \mathbf{F}$ \\
\hline $\begin{array}{l}\text { Jogjakarta (JOG) - } \\
\text { Majalengka (KJT) }\end{array}$ & 6 & - & - & $16,4 \%$ \\
\hline $\begin{array}{l}\text { Jakarta Halim (HLP) - } \\
\text { Majalengka (KJT) }\end{array}$ & 8 & - & - & $9,5 \%$ \\
\hline $\begin{array}{l}\text { Batam (BTH) - Majalengka } \\
(\mathrm{KJT})\end{array}$ & 368 & 294.625 & - & $76,5 \%$ \\
\hline $\begin{array}{l}\text { Majalengka (KJT) - Surabaya } \\
(\mathrm{SUB})\end{array}$ & 721 & 289.419 & - & $47,5 \%$ \\
\hline $\begin{array}{l}\text { Majalengka (KJT) - } \\
\text { Pekanbaru (PKU) }\end{array}$ & 411 & 40.002 & - & $42,2 \%$ \\
\hline $\begin{array}{l}\text { Denpasar (DPS) - } \\
\text { Majalengka (KJT) }\end{array}$ & 821 & 34.436 & - & $69,3 \%$ \\
\hline $\begin{array}{l}\text { Majalengka }(\mathrm{KJT}) \text { - Medan } \\
(\mathrm{KNO})\end{array}$ & 635 & 32.275 & - & $50,8 \%$ \\
\hline $\begin{array}{l}\text { Majalengka (KJT) - } \\
\text { Makassar (UPG) }\end{array}$ & 289 & 29.232 & - & $39,5 \%$ \\
\hline $\begin{array}{l}\text { Banjarmasin (BDJ) - } \\
\text { Majalengka (KJT) }\end{array}$ & 367 & 15.862 & - & $75,7 \%$ \\
\hline $\begin{array}{l}\text { Balikpapan (BPN) - } \\
\text { Majalengka (KJT) }\end{array}$ & 384 & 13.126 & - & $56,4 \%$ \\
\hline $\begin{array}{l}\text { Majalengka (KJT) - } \\
\text { Pontianak (PNK) }\end{array}$ & 132 & 1.666 & - & $37,9 \%$ \\
\hline $\begin{array}{l}\text { Lombok (LOP) - Majalengka } \\
(\text { KJT) }\end{array}$ & 100 & 784 & - & $30,7 \%$ \\
\hline $\begin{array}{l}\text { Majalengka (KJT) - } \\
\text { TanjungKarang (TKG) }\end{array}$ & 2 & 175 & - & $44,0 \%$ \\
\hline $\begin{array}{l}\text { Majalengka (KJT) - } \\
\text { Palembang (PLM) }\end{array}$ & 12 & 10 & - & $46,4 \%$ \\
\hline Jumlah & 4.256 & 744.612 & & \\
\hline
\end{tabular}

Desember 2019

Sumber: Kemenhub (2019) 
Tabel 2 Data Bandara Husein JuliDesember 2019

\begin{tabular}{|c|c|c|c|c|}
\hline Rute & $\begin{array}{l}\text { Jumlah } \\
\text { Pnb. }\end{array}$ & $\begin{array}{c}\text { Jumlah } \\
\text { Barang } \\
\text { (kg) }\end{array}$ & $\begin{array}{l}\text { Jml } \\
\text { Pos } \\
\text { (kg) }\end{array}$ & $\mathbf{L} / \mathbf{F}$ \\
\hline $\begin{array}{l}\text { Bandung (BDO)- } \\
\text { Banyuwangi (BWX) }\end{array}$ & 58 & - & - & $40,6 \%$ \\
\hline $\begin{array}{l}\text { Bandung (BDO) - } \\
\text { Surabaya (SUB) }\end{array}$ & 4.141 & 2.144 .203 & 1.530 & $69,1 \%$ \\
\hline $\begin{array}{l}\text { Bandung (BDO) - } \\
\text { Denpasar (DPS) }\end{array}$ & 1.977 & 1.109 .830 & - & $72,5 \%$ \\
\hline $\begin{array}{l}\text { Bandung (BDO)- } \\
\text { Palembang (PLM) }\end{array}$ & 723 & 895.388 & - & $70,3 \%$ \\
\hline $\begin{array}{l}\text { Bandung (BDO) - } \\
\text { Medan (KNO) }\end{array}$ & 1.050 & 722.673 & - & $76,7 \%$ \\
\hline $\begin{array}{l}\text { Bandung (BDO)- } \\
\text { Pekanbaru (PKU) }\end{array}$ & 711 & 531.091 & 6 & $64,3 \%$ \\
\hline $\begin{array}{l}\text { Bandung (BDO) - } \\
\text { Pontianak (PNK) }\end{array}$ & 360 & 442.155 & - & $73,0 \%$ \\
\hline $\begin{array}{l}\text { Bandung (BDO) - } \\
\text { Batam (BTH) }\end{array}$ & 362 & 414.062 & - & $84,2 \%$ \\
\hline $\begin{array}{l}\text { Bandung (BDO) - } \\
\text { Banjarmasin (BDJ) }\end{array}$ & 361 & 358.484 & 60 & $88,4 \%$ \\
\hline $\begin{array}{l}\text { Bandung (BDO) - } \\
\text { Makassar (UPG) }\end{array}$ & 361 & 342.295 & - & $84,5 \%$ \\
\hline $\begin{array}{l}\text { Balikpapan (BPN) - } \\
\text { Bandung (BDO) }\end{array}$ & 362 & 342.077 & - & $86,7 \%$ \\
\hline $\begin{array}{l}\text { Bandung (BDO) - } \\
\text { Padang (PDG) }\end{array}$ & 343 & 269.306 & - & $77,9 \%$ \\
\hline $\begin{array}{l}\text { Bandung (BDO) - } \\
\text { Jakarta Halim (HLP) }\end{array}$ & 2.459 & 239.481 & 234 & $77,3 \%$ \\
\hline $\begin{array}{l}\text { Bandung (BDO) - } \\
\text { Jogjakarta (JOG) }\end{array}$ & 1.460 & 96.436 & 448 & $72,1 \%$ \\
\hline $\begin{array}{l}\text { Bandung (BDO) - } \\
\text { TanjungKarang } \\
\text { (TKG) }\end{array}$ & 1.362 & 88.542 & 2.851 & $62,3 \%$ \\
\hline $\begin{array}{l}\text { Bandung (BDO) - } \\
\text { Semarang (SRG) }\end{array}$ & 1.743 & 40.320 & 298 & $60,3 \%$ \\
\hline $\begin{array}{l}\text { Bandung (BDO) - } \\
\text { Lombok (LOP) }\end{array}$ & 101 & 34.720 & - & $51,3 \%$ \\
\hline $\begin{array}{l}\text { Bandung (BDO) - } \\
\text { Pangkal pinang } \\
\text { (PGK) }\end{array}$ & 323 & 15.993 & 86 & $43,8 \%$ \\
\hline $\begin{array}{l}\text { Bandung (BDO) - } \\
\text { Solo (SOC) }\end{array}$ & 566 & 4.828 & 77 & $41,3 \%$ \\
\hline $\begin{array}{l}\text { Bandung (BDO) - } \\
\text { Bengkulu (BKS) }\end{array}$ & 161 & 4.379 & 44 & $38,1 \%$ \\
\hline $\begin{array}{l}\text { Bandung (BDO) - } \\
\text { Jambi (DJB) }\end{array}$ & 164 & 139 & 66 & $38,8 \%$ \\
\hline $\begin{array}{l}\text { Bandung (BDO) - } \\
\text { Tanjungpandan (TJQ) }\end{array}$ & 135 & 82 & 10 & $23,7 \%$ \\
\hline $\begin{array}{l}\text { Bandung (BDO) - } \\
\text { Malang (MLG) }\end{array}$ & 5 & 42 & - & $31,9 \%$ \\
\hline Jumlah & 19.288 & 8.096 .526 & 5.710 & \\
\hline
\end{tabular}

Sumber : Kemenhub (2019)

Dari tabel di atas didapat hasil sebagai berikut :

Data Bandara Husein
1. Jumlah penerbangan terbanyak, rute Bandung-Surabaya : 4.141 penerbangan. Jumlah penerbangan terkecil, rute Bandung - Malang : 5 penerbangan.

2. Jumlah barang terbanyak, rute BandungSurabaya : $2.144 .203 \mathrm{~kg}$. Jumlah barang terkecil, rute Bandung-Banyuwangi : nol $\mathrm{kg}$.

3. Jumlah pos terbanyak, rute BandungTanjung Karang : $2.851 \mathrm{~kg}$. Jumlah pos terkecil, rute Bandung-Malang, lombok, Banyuwangi, Denpasar, Palembang, Medan, Pontianak, Batam, Makasar, Padang, dan Balikpapan-Bandung.

Data Bandara Kertajati

1. Jumlah penerbangan terbanyak, rute Denpasar-Majalengka $\quad$ : $\quad 821$ penerbangan. Jumlah penerbangan terkecil, rute Majalengka-Tanjung Karang : 2 penerbangan.

2. Jumlah barang terbanyak, rute BatamMajalengka : $294.625 \mathrm{~kg}$. Jumlah barang terkecil, rute Jogyakarta-Majalengka, Halim-Majalengka: nol kg.

3. Jumlah pos tidak ada.

\section{BAHASAN PENELITIAN}

Penelitian ini membahas tentang peluang BIJB sebagai hub logistik internasional di Jawa Barat. 


\section{TEKNIK ANALISA DATA}

Langkah-langkah penelitian ini meliputi pengumpulan data, analisis data, membuat kesimpulan dan laporan.

\section{ANALISIS PENELITIAN}

Berdasarkan tabel di bawah ini dapat dilihat perbandingan jumlah penerbangan, jumlah barang, dan jumlah pos pada Bandara Kertajati dan Bandara Husein sebagai berikut :
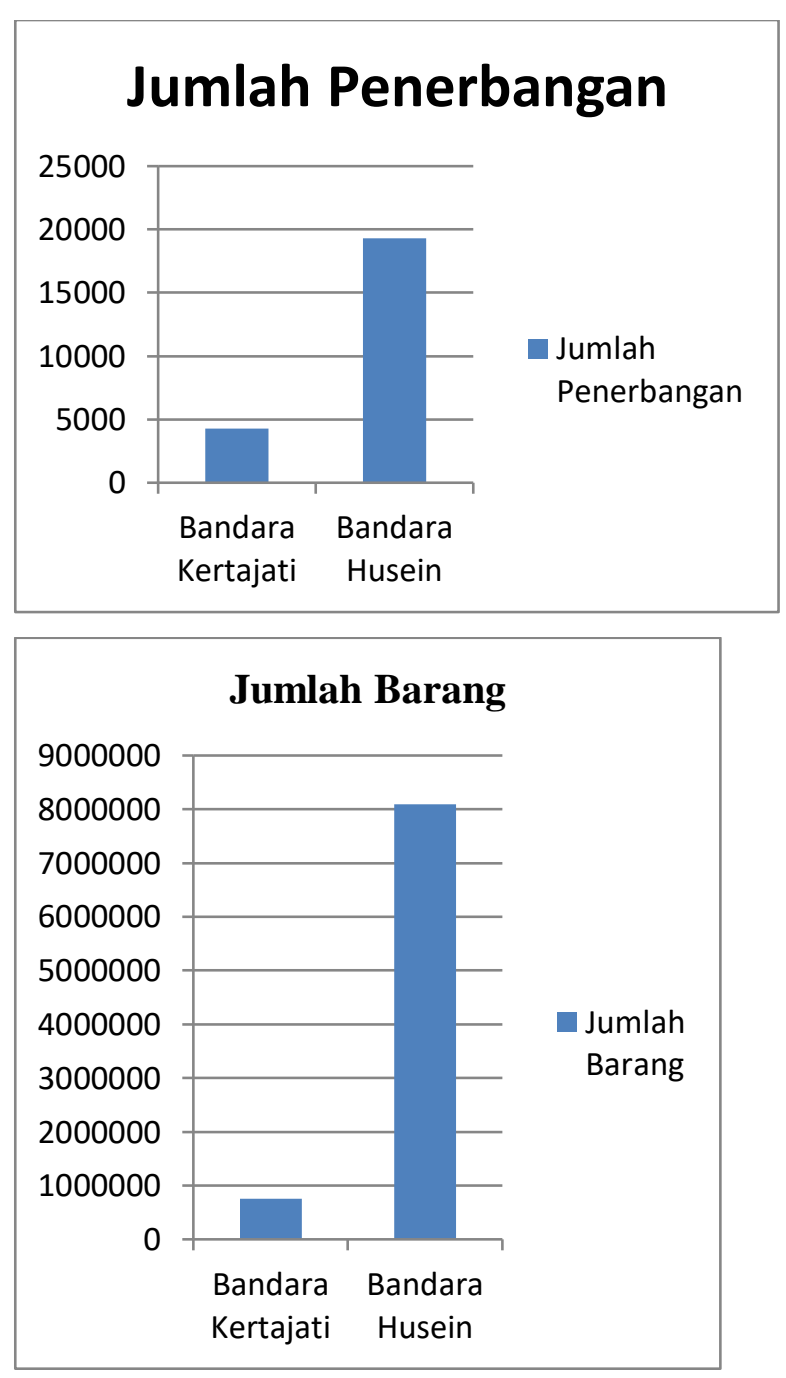

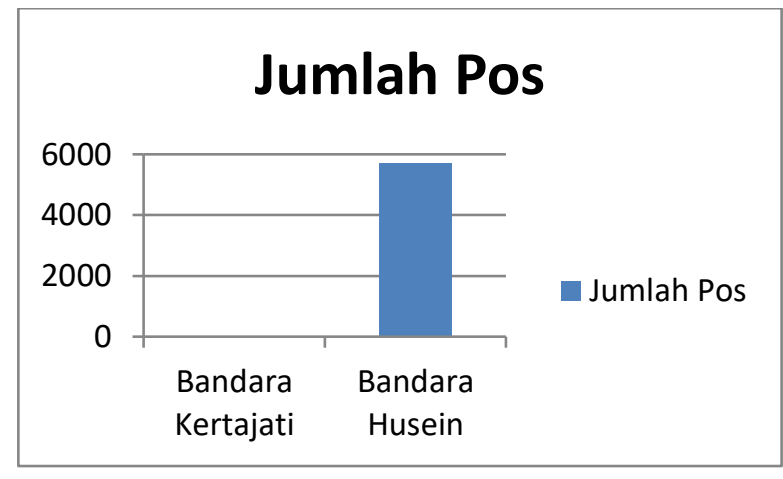

Menjadikan Bandara Kertajati di Majalengka sebagai hub logistik terutama untuk e-commerce akan menutupi kelemahan Bandara Soeta yaitu waktu tempuh yang lama dari/ke CGK bagi pasar Jakarta dengan lalu lintas yang sangat padat.

Peluang lainnya yaitu produk UKM Jabar dapat mendunia lebih cepat dengan dijadikannya Bandara Internasional Jawa Barat (BIJB) menjadi hub untuk kargo terbesar di Indonesia. Menurut Dirut PT Pos Logistik Indonesia, Yuzon Erman, hampir 60 per 100 industri nasional ada di Jawa Barat dan ribuan produk UKM juga hadir di Jawa Barat.

Dilihat dari volume kargo, dibandingkan dengan BIJB, volume kargo di CGK tetap tinggi walaupun pada masa wabah Covid 19. Hal ini bisa menjadi peluang bagi BIJB karena daya tampung kargo CGK hanya 1.643 ton per hari. Pada masa wabah saja CGK sudah mencapai 1.350 ton. Dibandingkan data 2019 beban CGK sudah mencapai 1.852 ton per hari atau sudah melebihi kapasitas sebanyak 208 ton per hari. 
Sebagian kelebihan kapasitas CGK ini perlu dialihkan ke Kertajati sehingga terjadi keseimbangan beban antara CGK dan BIJB. Volume kargo di Bandara CGK dapat dilihat pada grafik di bawah ini.

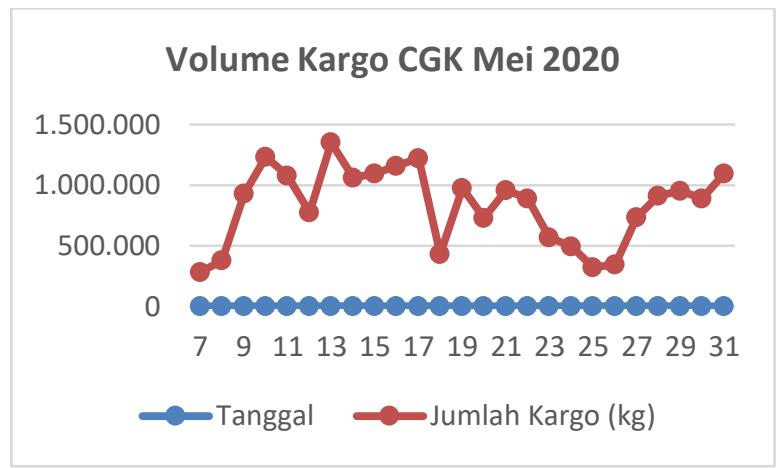

Grafik1 Volume Kargo Bandara CGK Mei 2020 Sumber: Angkasa Pura II (2020)

Angkutan kargo per Pax Paska Surat Edaran Kemenhub No. 31 tahun 2020 ratarata di CGK $272 \mathrm{~kg} /$ pax. Jika dilihat dari grafik di atas, volume kargo di Bandara Soeta tertinggi pada tanggal 13 Mei 2020 sejumlah 1.351 ton dan volume terendah pada tanggal 25 Mei 2020 sejumlah 324 ton serta rata-rata 834 ton per hari.

Kemampuan maksimal terminal kargo CGK adalah 1.640 ton per hari. Sekarang pada saat beban puncak sudah 1.350 ton per hari maka perlu segera diantisipasi pertumbuhan kargo ini dengan memanfaatkan BIJB sebagai penyeimbang beban CGK. Data CGK sebagai berikut:

\begin{tabular}{|l|l|}
\hline 2019/hari & 1.852 .390 \\
\hline Max/hari & 1.643 .836 \\
\hline
\end{tabular}

\begin{tabular}{|l|l|}
\hline Over/hari & 208.554 \\
\hline
\end{tabular}

Hub udara yang berhasil yaitu hub udara yang menawarkan layanan dan frekuensi udara yang banyak dan terhubung secara luas keseluruh bandara di wilayah ASEAN dan Australia serta berlokasi strategis di jaringan udara wilayah Indonesia. Jika BIJB Majalengka Jabar ingin benarbenar berhasil sebagai hub udara maka maskapai penerbangan harus dapat terbang ke dan dari Bandara Kertajati, serta memanfaatkannya sebagai titik transit di sepanjang perjalanan mereka.

Untuk meningkatkan kemampuan Majalengka memasuki pasar wilayah Asia Pasific, maka Kemenhub perlu membuat dan memasyarakatkan sebuah Kebijakan "slot terbuka" agar mendorong lebih banyak maskapai terbang ke Majalengka. Sebagai pusat logistik udara, Majalengka juga perlu menawarkan bahan bakar penerbangan dengan biaya yang lebih murah. Kebijakan "slot terbuka" serta Majalengka bebas konsesi dan/atau pajak daerah serta banyaknya perjanjian layanan udara dengan wilayah Asia Pasific akan membuat Majalengka menjadi hub udara yang menarik.

Untuk efisiensi, sebagian besar maskapai penerbangan yang ke Majalengka perlu mengadopsi model operasi 
transhipment "hub-and-spoke" yaitu maskapai menerbangkan penumpang dan barang dari bandara cabang ke bandara pusat wilayah atau hub. Hub wilayah ini kemudian berfokus pada penerbangan jarak jauh serta memanfaatkan pesawat yang lebih besar dan lebih efisien untuk mendapatkan keuntungan dari skala ekonomis.

Sebagai langkah awal, pengoperasian jalur KJT-XSP-BTH-KJT dapat memakai pesawat turboprop (mesin kipas) kargo dengan muatan pallet 5@88"x108" atau 9@88"x62" atau Bulk Payload sampai dengan 8.5 ton atau sampai $75 \mathrm{~m}^{3}$. Pesawat kargo turboprop tersebut dapat mendarat di bandara Seletar (XSP) dengan Jalur KJTSIN-BTH-KJT. Disamping itu terdapat juga pilihan memakai pesawat jet kargo dengan kapasitas pallet 10-11@125” x 88" atau 10 buah LD3 atau bulk dengan muatan yang dapat dijual 15 - 18 ton, atau sampai dengan $142 \mathrm{~m}^{3}$ dan mendarat di Bandara Changi (SIN).

Dari sisi pemerintah, perlu lebih cepat menyiapkan infrastruktur dan konsisten menyediakan moda transportasi dari pusat kota ke bandara maupun moda transportasi dari Kawasan Industri Karawang dan Kawasan Industri Brebes (Jawa Tengah bagian barat) ke BIJB.

Kinerja kargo udara di masa mendatang akan mengalami peningkatan dan Indonesia punya peluang dapat segera memanfaatkan drone kargo (cargo aerial vehicle) dan robotika (UAV atau Pesawat Udara Tanpa Awak). Penggunaan UAV bermanfaat untuk mengurangi keterlibatan langsung awak pesawat dan petugas dalam penerbangan. Hal tersebut sekaligus menjadi antisipasi wabah Covid-19 gelombang kedua dan/atau ketiga sehingga dapat memberikan keuntungan bagi BIJB untuk menyediakan lahan pergudangan yang bisa dijadikan landasan mendarat dan lepas landas UAV kargo.

\section{KESIMPULAN}

Beberapa hal yang didapat dalam pembahasan dapat diambil kesimpulan sebagai berikut :

1. Penyebaran kargo melalui Bandara KJT dapat mengurangi resiko keterlambatan pengiriman kargo.

2. Bandara Kertajati di Kabupaten Majalengka dianggap menjadi titik temu dan dianggap menjadi lokasi strategis sebagai pusat arus lalu lintas udara internasional dan logistik dari dua pelabuhan, yaitu Pelabuhan Muara Jati Cirebon dan Patimban.

3. Bandara Kertajati bisa menjadi bandara hub logistik untuk mendorong kegiatan UKM Jawa barat lebih terkenal ke seluruh pelosok negeri dan mancanegara. 


\section{SARAN}

1. Bandara Kertajati harus memiliki fasilitas yang cukup untuk mendukung Angkutan Logistik.

2. Adanya dukungan dari pemerintah, angkutan udara, perusahaan logistik dan masyarakat untuk menjadikan Bandara Kertajati ini menjadi Hub Logistik Internasional di Jawa Barat.

3. Kesiapan sumber daya manusia untuk mendukung Bandara Kertajati menjadi Hub Logistik Internasional di Jawa Barat.

\section{DAFTAR PUSTAKA}

Gunawan. Herry. 2014. Pengantar Transportasi dan Logistik. Jakarta: PT Raja Grafindo Persada.

Kementerian Perhubungan, Direktorat Angkutan Udara, 2019. Statistik Angkutan Udara Tahun 2019. Jakarta Pusat: Kementerian Perhubungan.

$$
\text { Rizaldy, Wynd dan Rifni, }
$$

Muhammad. 2013. Manajemen Dasar Penanganan Kargo (Udara Dari/Ke Laut via Darat). Jakarta: In Media.

Surat Edaran Kemenhub No. 31 tahun 2020. RI.

UU No. 01 tahun 2009 tentang Penerbangan. RI.

\section{INTERNET}

bijb.co.id https://suaramerdeka.news/dua-akses-tol-kekertajati/ https://bisnis.tempo.co/read/1261756/bandara -kertajati-akan-jadi-pusat-kawasan-logistike-commerce https://regional.kompas.com/read/2019/05/12 /19475591/infrastruktur-mendukungbandara-kertajati-akan-jadi-pusat-kargoterbesar?page $=$ all https://jabarprov.go.id/index.php/news/33008 /2019/05/11/BIJB-Jadi-Hub-Cargo-ProdukUKM-Jabar-Berpotensi-Mendunia-Lebih-

\section{Cepat}

www.angkasapura2.co.id 